\title{
JOSÉ MARIA ARGUEDAS: 0 DISCURSO DO HIBRIDISMO CULTURAL E DA QUEBRA DA IDENTIDADE NACIONAL
}

\author{
Alexandre Vieira ${ }^{1}$
}

Abstract: This work intends to make an analyse of the discourse of disconstruction of the national identity and cultural hybridism in the peruvian writer José Maria Arguedas' works. So that, we will make useful the theorizer Jacques Derrida's reflections that show the binary logic as a discourse creation, so, the opposite pairs don't exist originally, neither the division between light and darkness, truth and lie, and, extending for this work, between settled and settler. Above all, the myth, operating the synthesis between the national and the universal, makes a collapse in the idea of construction of the national identity. This work will also make complex the critique's point of view that understand the latin-american as a culture dependent on the called central cultures. The crossbreeding and the cultural anthropophagy produce a condensation between cultures and different people, breaking down the national identity idea. The Arguedas'works are characterized, so, for the mixture of styles and cultures, reflecting the cultures of the country whereof the writer lives.

Key-words: discourse, disconstruction, hybridism, identity, myth, Arguedas

Resumo: $O$ presente trabalho pretende fazer uma análise do discurso da desconstrução da identidade nacional e do hibridismo cultural na obra do escritor peruano José Maria Arguedas. Para isso, utilizarei a linha de pensamento do teórico Derrida que demonstra que a lógica binária é uma criação do discurso, pois os pares opostos não existiriam na origem, como a divisão entre luz e trevas, verdade e mentira, e, estendendo para este trabalho, entre colonizado e colonizador. Além disso, o mito, operando a síntese entre 0 nacional e o universal provoca um colapso na idéia da construção da identidade nacional. $O$ trabalho também irá complexificar o ponto de vista da crítica literária que aponta que a cultura latino-americana é dependente das culturas ditas centrais. A mestiçagem e a antropofagia cultural produzem uma condensação entre culturas e povos, quebrando com a idéia de identidade nacional. A obra de Arguedas se caracteriza, então, pela mistura de estilos e culturas, refletindo a cultura do país onde ele vive.

Palavras-chave: discurso, desconstrução, hibridismo, identidade, mito, Arguedas

\footnotetext{
1 Universidade Estadual do Rio de Janeiro.
} 


\section{INTRODUĢ̄̃̃O}

Tenho como objetivo, neste trabalho, analisar o imaginário mítico a partir da atualização de fontes míticas indígenas na prosa do escritor e antropólogo peruano José María Arguedas. Nesse sentido, procuro desenvolver uma visão desconstrutivista da relação binária colonizador/colonizado, assim como a diluição da noção de identidade nacional.

Para tanto, utilizo o método desconstrutivista, segundo a definição proposta no capítulo 1 do livro Gramatologia, "O fim do livro e o começo da escritura", em que Derrida critica o grau universalizante da visão estruturalista que reduz a complexidade dos fenômenos particulares numa tabela de oposições. Ele mostra os limites de certo "conceito de signo" e certo sentido das relações entre fala e escritura, determinadas pelo logocentrismo e etnocentrismo. A idéia de origem do mundo a partir da diferença é desconstruída pelo apagamento dos limites entre pares opostos, criando-se, assim, a extensão do conceito de línguagem através do jogo: "a desconstrução de todas as significações de logos. Em especial a significação de verdade."2 Assim, Derrida desconstrói aquilo que ele denomina uma filosofia da presença; filosofia que busca uma determinação do sentido através da proximidade absoluta da voz e da identidade do ser, da voz e da identidade do sentido (fonocentrismo). Esse ataque ao caráter duplo do signo leva Derrida a trabalhar com a ambigüidade, com o jogo. O autor critica o postulado de "uma verdade ou um sentido já constituídos pelo e no elemento do logos". ${ }^{3}$ Dessa forma, ele pretende desconstruir a unidade constitutiva da palavra fundada pela metafísica da presença logocêntrica, desestabilizando a unidade de sentido do ser, que é, por isso mesmo, a unidade da palavra. Dessa forma, as relações binárias e hierárquicas entre luz e trevas, forma e conteúdo são desconstruídas, pois tais oposições não teriam uma origem, seriam antes construções discursivas, fundadas pela condição "logocêntrica" e mantidas dentro de uma concepção estrita de "escritura". Neste texto, amplio o ânimo desconstrutor para a relação entre colonizador e colonizado, diluindo também o sentido de identidade nacional, que seria construída pelos romances indianistas.

O intuito deste trabalho é complexificar a visão que a crítica literária tem da relação de dependência da literatura latino-americana às fontes européias. $\mathrm{O}$ resgate do mito, operando a síntese entre o nacional, o particular e o universal, o arquetípico, realiza, nas obras de Arguedas, uma condensação a partir da línguagem, que escapa à noção de dependência. Assim, a questão

2 DERRIDA, Jacques. Gramatologia. Tradução de Miriam Schnnaiderman e Renato Janini Ribeiro. São Paulo: Perspectiva, 1973, p.13.

3 Idem, p. 18. 
da mestiçagem, por exemplo, já se vislumbra no próprio terreno do mito, antes que este se transforme em matéria-prima do fazer literário.

\section{A OBRA DE JOSÉ MARIA ARGUEDAS}

Arguedas, que viveu e cresceu no meio dos quíchuas, mostra em seus romances o choque de duas culturas, a trágica contradição de dois espaços: a costa e a serra. Ele incita, através de suas obras, a consciência dos peruanos para que enfrentem o drama da opressão em que os povos indígenas vivem. Valoriza as raízes peruanas, em contraste, não dialético, com o desenraizamento produzido na costa. A sociedade do Peru é um misto entre uma maioria de índios de origem incaica, uma camada intermediária de cholos mestiços de índios e brancos, e uma minoria branca.

Vemos na obra de Arguedas a mescla entre várias temporalidades e culturas no interior do país onde ele vive. A questão fundamental que está em sua obra é um país dividido em duas culturas - a andina, de origem quíchua, e a urbana, de raízes européias - que se devem interar em uma relação dialógica de caráter mestiço. Nos três contos da primeira edição de Agua (1935), em seu primeiro romance Yamar fiesta (1941) e na recompilação de Diamantes y pedernales (1954), se encontra o esforço de o autor oferecer uma versão mais autêntica possível da vida andina desde um ponto de vista mais interiorizado e sem o conservadorismo da literatura indigenista de cunho engajado e redutor. Nessas obras, Arguedas valoriza o modo de vida de ser índio, sem se deixar levar por um ponto de vista dialético, apresentando por outro lado a cultura cosmopolita e desenvolvida que é influenciada pelos países capitalistas "superiores". Isso contradiz uma visão binária e redutora entre centro e periferia, costa e serra, apresentando o autor um desejo utópico, a partir da mestiçagem cultural, de as origens primevas da tradição cultural andina permanecerem na época de grandes transformações industriais. Desenvolve as linhas de pensamento marxista de José Carlos Mariátegui e a obra de Ciro Alegría, oferecendo importantes semelhanças e diferenças. A obra posterior de Arguedas compreende essencialmente três romances: Los ríos profundos (1956), Todas las sangres (1964) e El zorro de arriba y el zorro de abajo (1971), sendo esta última uma obra póstuma. De todas essas obras, a que mais impressiona pelo seu lirismo mágico e encantatório do imaginário mítico indígena, com sua vontade transcendente de unidade cósmica perdida na busca de totalidade, é Los ríos profundos, em que temos a relação harmônica do homem com a natureza e a permanência das tradições indígenas. Seu grande esforço é apresentar as várias tonalidades de seu país, em intenso processo de mestiçagem cultural e lingüística. $\mathrm{O}$ narrador-personagem deste romance apresenta um retorno à harmonia 
mítica, profunda; um contato com as coisas em sua sacralidade e antigüidade. Para isso, utiliza palavras do vocabulário quíchua, significativas para o narrador e suas impressões sobre o meio, associando imagens inusitadas: "Era estático o muro, mas fervia por todas as suas linhas e a superfície se transformava, como a dos rios no verão, que têm um cume assim, lá pelo meio do caudal, sua zona temível, a mais poderosa. Os índios chamam "Yamar mayu" a esses rios turvos, porque exibem com o sol um brilho em movimento, semelhante ao do sangue."

O narrador-personagem tem o intenso conhecimento da línguagem e cultura indígenas. Ele é branco, vive a mestiçagem lingüística e cultural em suas constantes viagens pelas aldeias indígenas com seu pai. A mistura não é apenas lingüística, está também inscrita no espaço físico da cidade, em sua estrutura arquitetônica: "- Esta praça é espanhola? - Não. A praça não. Os arcos, os templos. A praça não. Foi feita por Pachakutek', o Inca renovador do mundo.",

Aqui, a tradição mítica é amalgamada na tradição espanhola, mostrando um mundo de correspondências entre as formas. Tudo em Cuzco, por onde o narrador-personagem passa, no início do romance, leva-o a associar imagens com relação ao imaginário mítico, que já está enformado em sua mente. A línguagem do narrador é mítica e, ao mesmo tempo, moderna. Mas não é apenas o protagonista que apresenta essa línguagem mestiça. No internato, em que ele passa a morar, o discurso das outras personagens é híbrido, entre o Espanhol e o quíchua. O espaço mítico invade o colégio de Abancay na narrativa do protagonista Ernesto: "Os internos se dispersavam, tratando de não roçar muito o chão, de não fazer nenhum ruído, como se no pátio dormisse um grande inimigo, um nanak'."6 Por outro lado, o ambiente de brigas, de desuniões, que leva à desarmonia entre os internos no pátio do colégio, contrapõe-se, simbolicamente, ao ambiente mítico de harmonia das lembranças de Ernesto: "Nenhum pensamento, nenhuma recordação podia chegar até o isolamento mortal que durante aquele tempo me separava do mundo (...) Mas na hora em que voltava daquele pátio, ao anoitecer, desprendia-se de meus olhos a imagem maternal do mundo." 7

A imagem da ponte, no capítulo $\mathrm{V}$, demonstra esse caráter mestiço, em que ela representa o símbolo do espaço do colonizador espanhol e do espaço mítico da natureza. A ponte polariza e funde dois mundos: "A ponte do $\mathrm{Pa}$ chachaca foi construída pelos espanhóis. Tem dois olhos altos, sustentados

${ }^{4}$ ARGUEDAS, José Maria. Os rios profundos. Tradução de Gloria Rodriguez. Rio de Janeiro: Paz e Terra, 1977, pp. 12-13.

${ }^{5}$ Idem, p.15.

6 Idem, ibid, p.59.

${ }^{7}$ Idem, ibid, p.59. 
por bases de alvenaria, tão poderosas como o rio (...) Eu não sabia o que mais amava, se a ponte ou o rio. Mas ambas desanuviavam minha alma, inundavam-na de fortaleza e de sonhos heróicos." 8

A profundidade do imaginário mítico se sustém na descrição do rio, imaginário que está inserido tanto na realidade quanto na fala do narrador, sendo um signo um reflexo do real, mais ainda intensificado pela línguagem literária: "Sim! Era preciso ser como aquele rio imperturbável e cristalino, como suas águas triunfais. Como tu, rio Pachachaca! Belo cavalo de crina brilhante, incontido e permanente, que marcha pelo mais profundo caminho terrestre!"9

\section{O DISEURSO DO HIBRIDISMO CULTURAL E DA QUEBRA DA IDENTIDADE NACIONAL}

A análise anteriormente esboçada ajuda a definir a forma de abordagem de meu estudo sobre José María Arguedas, ou seja, procuro identificar sinais do hibridismo cultural tanto no nível da línguagem quanto no nível dos temas abordados em suas obras.

Deste modo, é fundamental observar que o escritor peruano também trabalhou com uma línguagem igualmente mestiça. Utilizou o quíchua numa realização literária que teve de fazer valer também o idioma do dominador. Produz uma "indigenização" da voz dominante: a mescla do Espanhol mais convencional e também as marcas da oralidade, linhas encantatórias que ampliam a poeticidade de seu discurso. Analisa a cultura que habita desde um tempo impreciso o interior do país: uma voz mítica, um tempo primevo com a posterior agressão externa, de injustiça que acossa essa cultura, produzindo um movimento de suposta "aculturação", pois os elementos são amalgamados numa fusão mestiça. Sua obra, porém, apresenta a angústia dessa opressão das culturas indígenas. Em seus três livros mais importantes, citados anteriormente, apresenta a desagregação do universo ameaçado, a possibilidade de destruição dos liames míticos, da harmonia primordial e fundacional, como em Los ríos profundos. A serra, como espaço do sagrado, depositária das tradições mágicas, é solapada pela exploração inumana e racionalizada da costa. $\mathrm{O}$ autor demonstra sua esperança em um mundo novo, fruto da mestiçagem. O processo de declinação final culmina com El zorro de arriba y el zorro de abajo, em que há um maior hibridismo entre uma línguagem das tradições mais antigas e os movimentos de vanguarda. Nessa obra, Arguedas apresenta-se como um rapsodo da tradição indígena, demonstrando o drama de sua mensagem mesti

${ }^{8}$ Idem, ibid, p.63.

9 Idem, ibid, p.63.

66 VOLUME 2, NÚMERO 2, 2006 
ça. Chimbote se configura como símbolo da devastação e da desagregação da sociedade peruana. "El zorro de arriba y el zorro de abajo": essa expressão o autor tomou de um manuscrito quíchua recolhido por Francisco de Avila, que Arguedas havia traduzido, com muitas dificuldades, para o Espanhol em 1966. Os capítulos narrativos são dedicados ao mundo degradado de Chimbote, microcosmo que reúne as trocas econômicas e sócio-culturais que afetam o país, como nação periférica. Uma espécie de Babilônia mítica, em que imperam todas as línguagens e vivências, cidade cosmopolita com vários níveis sociais, é um lugar prosaico e fragmentado, ao mesmo tempo, mágico, fora até da temporalidade racional. A obra se configura como uma narração mítica e realista. Ao mesmo tempo, temos a narrativa sobre Chimbote e na outra parte os "Diários" do narrador José María Arguedas, apresentando momentos da vida do escritor. Esta obra de Arguedas é uma colagem de vários tipos de textos, sendo heterogênea: parte vivida e parte ficcional. O autor também mostra os movimentos de migração e a dolorosa adaptação dos serranos ao mundo dos trabalhadores da costa em busca de fusão cultural. A essa estratificação étnica corresponde uma estrutura social que tende a estigmatizar o índio com o desprezo nacional. Arguedas busca resgatar os valores da cultura nativa, impondo-os como elementos formadores de uma sociedade mais justa. Em Los ríos profundos, mostra um Peru, ao mesmo tempo profundo e real, com riqueza espiritual dos índios, identificando-os com o mundo andino; quis configurá-lo em sua totalidade (num desejo de coincidentia oppositorum mítica) - o presente ligado ao passado mítico-histórico, utilizando uma línguagem altamente poética em face de um lugar oprimido.

Por outro lado, temos os movimentos de migração da costa para o interior. As aglomerações do Pacífico tendem a se interiorizar, fenômeno imitativo dos países industrializados, com o conseqüente amalgamento dos campesinos indígenas, formando o processo maior de mestiçagem.

Rubén Bareiro Saguier, no ensaio "José María Arguedas e la palabra herida", afirma sobre a línguagem de Arguedas:

...en un lenguaje matizado que rehúye el tipismo y rechaza el miserabilismo, Arguedas asume ese pedazo oculto y mágico de su mundo mestizo, reinvindica - sin programas ni proyectos reductores - su identidad profunda, en la cual los valores indígenas están presentes con la espontaneidad fervorosa de quien los ha vivido en la práctica cotidiana. ${ }^{10}$

\footnotetext{
10 In: ARGUEDAS, José Maria. El zorro de arriba y el zorro de abajo. Edición crítica. Eve-Maria Fell (coordinadora). $2^{\mathrm{a}}$ ed. Madrid; Paris; México; Buenos Aires; São Paulo; Rio de Janeiro; Lima: ALLCA XX, 1996, p. XVI.
} 
Em El zorro de arriba y el zorro de abajo, temos o movimento cosmogônico e desejável do autor no aniquilamento do estado caótico de Chimbote para a fundação do novo cosmos (ideário mítico). Apresenta, portanto, a fé da velha cultura mítica popular inserida numa outra fé, uma nova teologia a partir dessa fase culminante de crise através da figura de um "deus liberador" na sua "Teologia da liberação". Muitos observaram, nessa concepção, a influência de Gustavo Gutiérrez. O seu esforço de uma unificação de fatores heterogêneos, a mestiçagem entre o elemento antigo (andino) e elementos vanguardistas também estão presentes: a oralidade do conjunto da obra, a desagregação dos discursos, o jogo "arriba/abajo" e a tradição oral de tipo mágico.

A "Teologia da liberação", no Peru, resgata formas renovadas da espiritualidade cristã, em que há a citação da "Carta aos Coríntios", de São Paulo (XIII), influenciado pela Igreja, mostra um novo compromisso eclesiástico solidário com os pobres. $\mathrm{Na}$ "Introducción de la coordinadora", Eve-Marie Fell diz:

Por una parte, El zorro de arriba...remite al lector occidental a la bien conocida novela urbana de vanguardia, cuya composición de tipo entrecortado y yuxstapositorio refleja da fragmentación y concentración de las masas humanas en las metrópolis...Por otra parte, la obra de Arguedas se nutre de una larga tradición mágico-mítica andina, en torno a los dos zorros que reorganizan el espacio según la cosmovisión dual de los quechuas. ${ }^{11}$

A principal característica inserida na "Teologia da liberação" é a esperança. Haveria uma grande diferença dessa experiência entre o conhecimento mítico e o mundo da esperança cristã? Esse fator não aproximaria os dois imaginários, mostrando como os dois espaços são intercambiáveis? A figura do "Deus liberador", de certa forma, representa também aquele lugar da harmonia mítica que se encontra nos povos antigos, tempo da Primeira Natureza, a face da coincidentia oppositorum, que funde todas as coisas. Nas palavras do próprio Arguedas, temos a figuração desse Deus amalgamador: "Todo hombre que salga de sí mismo, que aspire a um amor universal, que encuentra aunténticamente al otro, estará encontrando a Dios y estará en el camino de la salvación." 12 A escolha de Arguedas foi certeira quanto ao espaço de mestiçagem cultural: o porto - metonímia da transformação e intersecção de culturas no Peru - lugar fronteiriço, de encontro entre o eu e o outro. Numa carta ao editor Carlos Barral, em 26 de julho de 1966, Arguedas já apresentava sua proposta em relação à imagem do porto: "Fui testigo de la transformación del puerto y de sus gentes. De cómo esta silenciosa y paradi

\footnotetext{
11 Idem, p. XXVI.

12 Apud ROULLÓN, José Luis. "La luz que nadie apagará. Aproximaciones al mito y al cristianismo en el último Arguedas". In: ARGUEDAS, José Maria. El zorro de arriba y el zorro de abajo, op. cit., p. 357.
} 
síaca caleta se convirtió en una especie de urbe entremezclada de negros, cholos, indios monolingües quechuas, chinos e injertos, prostitutas, ladrones y de empresarios sin entrañas." 13

O espaço do porto mescla dois tempos, o testemunho do homem atual e do homem da tradição mítica, em que as fronteiras não parecem tão importantes, mas o hibridismo e o processo de mestiçagem que ocorre entre os tempos. Descreve o Peru atual, em que a costa e a serra se fundem num movimento de atração que somente a línguagem artística pode expressar. $\mathrm{O}$ diálogo presente no romance é um outro discurso, o do sonho, que se situa também em outro tempo, o do mito, da origem, atualizando o arcaico, o oral, vinculando-se à fábula da tradição indígena, com o romancear moderno do mundo de Chimbote. Essa mescla expressa a própria dimensão do literário, como línguagem plural e que se expressa por camadas que se justapõem, sem ter uma forma dominante, com posições hierárquicas, mas no tempo circular da narrativa. As línguagens da Bíblia se unem a um discurso híbrido, em que passagens de "Isaías" se confundem com a da personagem don Esteban de la Cruz, padre que representa esse recurso à "Teologia da liberação", apresentando um triunfo final da humanidade através da esperança, que também está presente num mito quíchua da nova humanidade: "Este homanidade va desaparecer, otro va nacer del garganta del Esaias." 14 A mensagem do romance de Arguedas, com sua referência ao mundo mítico originário e com remissão a um futuro utópico, tem que se contradizer, com a observação do presente realístico, à vida social de Chimbote, que Arguedas observou com procedimentos e métodos de um antropólogo. Mas esse espaço não é apenas urbano, pois as estruturas míticas invadem o espaço dessa cidade cosmopolita. O espaço da costa, nessa obra, contrapõe-se ao cenário serrano de Todas las sangres e dos relatos que ocorrem nos Andes. O mundo de Chimbote, descrito de forma teleológica pelo louco Moncada (o que nos fornece uma narrativa mais onírica e mítica, devido a esse problema narrativo), nos oferece a imagem mesclada do que José Maria Arguedas nos tinha apresentado de seus livros anteriores. Essa cidade portuária, na verdade, perde suas raízes identitárias, inserindo-se num processo profundo de desagregação, que leva à mestiçagem, como desejo utópico projetado no futuro numa nova criação cosmogônica:

\footnotetext{
13 Citado por ARGUEDAS, Sybila Arredondo de. "El zorro de arriba y el zorro de abajo en la correspondência de Arguedas". In: ARGUEDAS, José Maria. El zorro de arriba e el zorro de abajo, op. cit., p. 276.

14 In: ROUILLÓN, op. cit., p.353.
} 
Ningún indio tiene pátria, ¿no? Me consta. No saben pronunciar ni el nombre de su provincia. Ningún cholo, ningún negro verdadero, zambo o injerto tienen concierto entre ellos. Son peores que los indios en eso. ¿Dónde está la patria, amigo? Ni en el corazón ni en la saliva. '¡A la mierda!', es el juramento de los cholos, injertos y negros; y los indios son una manada. ¡Ahí están! En los médanos y zancudales, robándose los unos a los otros. 'A la mierda.'15

Aqui, "aparentemente", parece haver um processo de aculturação total. Mas, na verdade, a nacionalidade imaginada por José María Arguedas propõe a união de distintas etnias, culturas e classes sociais. A perda das raízes não aponta para o processo de "aculturação", mas para a construção de um vínculo com outra cultura, que não é totalizante. De acordo com Roland Forgues, no ensaio "Por qué bailan los zorros"16, a "aculturação" lingüística está presente nesse último romance de Arguedas, pois Bazalar, uma das personagens do livro, é incapaz de pensar em quíchua, sua língua nativa. Para ele, a verdadeira mestiçagem ocorre em outro nível: o espaço do mito, em que a união de Maxwell e de Paratía representa a união mítica entre a costa e a serra. De acordo com Forgues, a mestiçagem perderia sua existência no mundo real para se fazer apenas presente a partir do espaço ideal do mito.

No romance póstumo de Arguedas, aparecem os "zorros" míticos que servem para comentar os acontecimentos. A forma romanceada assume, assim, diretamente a orientação da linha fundamental de Arguedas: revalorizar os aspectos míticos da experiência primordial, os heróis míticos de Huarochirí, que voltam a se encontrar agora, após longos anos de separação, no espaço cosmopolita e atual de Chimbote, para fazer juízos de valor sobre os atos humanos, misturando assim o discurso mítico - que não apresenta condenação - com características do discurso filosófico e reflexivo, que julga e pondera.

No último diário, terminando o romance, temos a descrição dos "zorros" míticos, que, realmente, dão o ponto final à narrativa:

Los zorros corren del uno al otro de sus mundos; bailan bajo la luz azul, sosteniendo trozos de bosta agusanada sobre la cabeza. Ellos sienten, musian, más claro, más denso que los medio locos transidos y conscientes y, por eso, y no siendo mortales, de algún modo hilvanan e iban a seguir hilvanando los materiales y almas que empezó a arrastrar este relato. ${ }^{17}$

\footnotetext{
${ }^{15}$ ARGUEDAS. El zorro de arriba y el zorro de abajo, op. cit., p.116.

16 In: ARGUEDAS. El zorro de arriba y el zorro de abajo, op. cit. 116.

17 Idem, ibid, pp. 244-245.
}

70 VOLUME 2, NÚMERO 2, 2006 


\section{CONSIDERACÕ̃ES FINAIS}

O objetivo do presente trabalho foi avaliar a necessidade de reinvenção e diálogo constante do mito ao longo das épocas, concretizando-se de forma criativa nos romances estudados, que, por sua vez, rejeitam a concepção de uma línguagem nacional e de um mito indígena inteiramente nacional, já que a mestiçagem não só lingüística, mas também mítica, opera a síntese que quebra com a idéia de representatividade mimética da identidade nacional. Para isso, utilizei como linha de pensamento a desconstrução apresentada pelo pensador Jacques Derrida, que se adequou ao jogo híbrido da coincidentia oppositorum do mito, quebrando a estrutura dialética do poder logocêntrico. $\mathrm{O}$ trabalho com o mito, operando a junção entre pares opostos como o particular e o universal, realizou, nos romances apresentados, uma condensação a partir da línguagem literária, plural e híbrida; transformou a noção de dependência no processo antropofágico deglutidor da cultura não só européia, mas clássica em sua concepção mais universalizante para transformar e devolver criativamente um trabalho mais amplo de perlaboração do outro em face do mesmo.

Portanto, podemos perceber como Arguedas não se prende a uma visão unilateral, perfazendo a lógica binária estruturalista. Antes, nos apresenta um mosaico mestiço em suas obras, tanto no âmbito conteudístico quanto formal, que fragmentam a visão de uma unidade nacional etnicamente purificada. O jogo de arriba (serra) e abajo (costa) se faz no espaço fronteiriço do porto, que nos apresenta o processo não de total desagregação e aculturação do Peru, mas sua constituição como uma nação híbrida que dialoga antropofagicamente com o outro.

\section{REFERÊNGIAS}

ANDRADE, Oswald de. Obras completas. V. 6. Do Pau-Brasil à Antropofagia e às Utopias. Manifestos, teses de concursos e ensaios. Rio de Janeiro: MEC/Civilização Brasileira, 1978.

ARGUEDAS, José María. Os rios profundos. Tradução de Gloria Rodríguez. Rio de Janeiro: Paz e Terra, 1977.

El zorro de arriba y el zorro de abajo. Edición crítica. Eve-Marie Fell (coordinadora). $2^{\mathrm{a}}$ ed. Madrid; París; México; Buenos Aires; São Paulo; Río de Janeiro; Lima: ALLCA XX, 1996.

ARGUEDAS, Sybila Arredondo de. "El zorro de arriba y el zorro de abajo en la correspondencia de Arguedas". In: ARGUEDAS, José Maria. El zorro de arriba y el zorro de abajo. Edición crítica. EveMarie Fell (coordinadora). 2a ed. Madrid; París; México; Buenos Aires; São Paulo; Río de Janeiro; Lima: ALLCA XX, 1996.

BHABHA, Homi K. O local da cultura. Tradução de Myriam Avila, Eliana Lourenço de Lima Reis, Glaucia Renato Gonçalves. Belo Horizonte: Ed. da UFMG, 1998.

BíBLIA. São Paulo: FTD. Petrópolis: Vozes, 1995.

CONEXÃO LETRAS 
DERRIDA, Jacques. Gramatologia. Tradução de Miriam Schnnaiderman e Renato Janini Ribeiro. São Paulo: Perspectiva, 1973.

ELIADE, Mircea. Aspectos do mito. Tradução de Manuela Torres. Lisboa: Edições 70, s.d. . Mito e realidade. Tradução de Pola Cirelli. São Paulo: Perspectiva, 1991.

FELL, Eve-Marie. "Introducción de la coordinadora". In: ARGUEDAS, José Maria. El zorro de arriba y el zorro de abajo. Edición crítica. Eve-Marie Fell (coordinadora). 2a ed. Madrid; París; México; Buenos Aires; São Paulo; Río de Janeiro; Lima: ALLCA XX, 1996.

GRUZINSKI, Serge. O pensamento mestiço. Tradução de Rosa Freire d' Aguiar. São Paulo: Companhia das Letras, 2001.

LÉVI-STRAUSS, Claude. O Pensamento selvagem. Tradução de Tania Pellegrini. São Paulo: Papirus, 1997.

LUKÁCS, Georg. Teoria do romance. Tradução de Alfredo Margarido. Lisboa: Editorial Presença, s.d.

ROCHA, João Cezar de Castro. "Um tempo antropófago para um espaço multicultural. Notas sobre antropofagia e multiculturalismo". In: As Américas do Sul: O Brasil no contexto Latino-Americano. s.l. Tübinger: Max Niemeyer, 2001.

ROUILLÓN, José Luis. "La luz que nadie apagará. Aproximaciones al mito y al cristianismo en el último Arguedas". In: ARGUEDAS. El zorro de arriba y el zorro de abajo; édicion critica, Eve-Marie Fell (coord.). 2.ed. Madrid; Paris, Mexico; Buenos Aires; Rio de Janeiro; Lima: ALLCA XX, 1996.

SAGUIER, Rubén Bareiro. "José Maria Arguedas e la palabra herida." In: ARGUEDAS. El zorro de arriba y el zorro de abajo; édicion critica, Eve-Marie Fell (coord.). 2.ed. Madrid; Paris, Mexico; Buenos Aires; Rio de Janeiro; Lima: ALLCA XX, 1996.

72 VOLUME 2, NÚMERO 2, 2006 